\title{
DESCRIÇÃO DE TRÊS NOVAS ESPÉCIES DO GÊNERO Melittomma (COLEOPTERA: LYMEXYLIDAE) DA REGIÃO NEOTROPICAL E CONSIDERAÇÕES SOBRE Melittomma brasiliense (CASTELNAU, 1832) ${ }^{1}$.
}

\section{Cláudio Ruy Vasconcelos da FONSECA ${ }^{2}$, Maria de Fátima VIEIRA ${ }^{3}$}

RESUMO - Estudo taxonômico das espécies neotropicais de Melittomma é apresentado, enfatizando as espécies distribuídas no território brasileiro. Discute-se brevemente os caracteres diagnósticos de $M$. brasiliense com dados de sua distribuição geográfica; descrições e ilustrações de três novas espécies, Melittomma nana sp.n. distribuida pela região Neotropical, $M$. brunnea sp.n. da Amazônia Central e M. panamensis sp.n. do Panamá, são apresentadas.

Palavras-chave: Amazônia; Coleoptera; Lymexylidae; Melittomma; Taxonomia

Description of three new species belonging to Genus Melittomma (Coleoptera, Lymexylidae) in the Neotropical region with annotations about Melittomma brasiliense (Castelnau, 1832).

\begin{abstract}
A taxonomic study of the neotropical species belonging to Melittomma is given, emphasizing those species distributed on Brazilian territory. A short discussion about diagnostic characters for $M$. brasiliense is given with data of its geographical distribution; descriptions and illustrations of three new species, Melittomma nana sp.n. distributed on Neotropical region, $M$. brunnea sp.n. from Central Amazon basin and M. panamensis sp.n. from Panama area, are presented.
\end{abstract}

Key-words. Amazonia; Coleoptera; Lymexylidae; Melittomma; Taxonomy

\section{INTRODUÇÃO}

A família Lymexylidae carrega muita controvérsia taxonômica ao longo de sua história, ora pertencendo aos Cleroidea, ora aos Telegeusidae e Cantharoidea. Entretanto, foi Leng (1920) quem colocou os limites da família, ratificados por vários autores, entre eles, Crowson (1981), Lawrence \& Newton $(1982,1995)$, Wheeler (1986).

Com distribuição pantropical, os Lymexylidae são um grupo pouco conhecido do ponto de vista comportamental e ecológico, com alguns trabalhos sobre Atractocerus, da ilha de Madagascar, devido seu interesse econômico. Do ponto de vista taxonômico também não são muitos os trabalhos especialmente para a região Neotropical, e por esta razão fez-se este estudo das espécies neotropicais de Melittomma, tomandose como ponto de partida o trabalho de Lane (1955). A terminologia aqui empregada segue a sugerida por Wheeler (1986). O material examinado foi proveniente de coletas realizadas pelos autores, bem como das coleções de várias instituições de pesquisas listadas a seguir:

INPA - Instituto Nacional de Pesquisa da Amazônia, Manaus, Brasil

\footnotetext{
${ }^{1}$ Trabalho financiado pelo convênio INPA/MAX-PLANCK

2,3 Instituto Nacional de Pesquisas da Amazônia, Coordenação de Pesquisas em Entomologia, Caixa Postal 478, Manaus - AM, 69011-970 - Brasil ; E-MAIL rclaudio@inpa.gov.br; mfvieira@inpa.gov.br
} 
MPEG - Museu Paraense Emílio Goeldi, Belém, Brasil

FUA - Fundação Universidade do Amazonas, Manaus, Brasil

MZSP - Museu de Zoologia da Universidade de São Paulo, São Paulo, Brasil

DZUP - Universidade Federal do Paraná, Curitiba, Brasil

UFV - Universidade Federal de Viçosa, Viçosa, Brasil

MCNZ - Museu de Ciências Naturais, Fundação Zoobotânica do Rio Grande do Sul, Porto Alegre, Brasil

MNRJ - Museu Nacional do Rio de Janeiro, Rio de Janeiro, Brasil

NHM - The Natural History Museum, London, UK.

USNM - National Museum of Natural History, Smithsoniam Institution, Washington, E.U.A.

\section{Histórico do Gênero}

$\mathrm{O}$ gênero Melittomma foi proposto por Murray (1867), sendo estudado posteriormente por Gorhan (1881) e por Kurosawa (1985) que arrolou as espécies asiáticas. Em 1955, Lane fez comentários sobre as espécies neotropicais, sugerindo que M. lateritium e $M$. marginellum poderiam ser sinônimos de $M$. brasiliensis, após constatar que os exemplares por ele identificados como pertencendo à última espécie, correspondiam também às descrições de Farmaire (1887) para $M$. lateritium e de Schenkling (1914) para $M$. marginellum. Para $M$. africanum, Lane aventou a hipótese de tratar-se de mais um sinônimo de $M$. brasiliensis, uma vez que a descrição de Thomson (1858) é pouco clara em sua diagnose. Além disso, concordou com Gorhan (1881) quando disse ser possivel $M$. africanum ter sido introduzido no Brasil através das rotas comerciais com a África durante o período colonial ou introduzidos na África do mesmo modo.

Wheeler (1986) incluiu no gênero 17 espécies ratificando a validade de $M$. lateritium e $M$. marginellum, mas neste trabalho será seguida a orientação de Lane (1955) considerando que não foram encontradas diferenças significantes na morfologia externa e nem tampouco na genitália daquelas espécies quando comparadas com $M$. brasiliensis. M. pubicolle Pic, 1944 não será incluida neste trabalho devido a sua ausência nas coleções examinadas, além de não terem os autores acesso ao trabalho onde está a sua descrição original.

\section{Melittomma brasiliense (Castelnau, 1832)}

Por ter merecido comentários de diversos autores, principalmente Lane (1955) que estabelece os limites de Melittomma, não será necessário redescrever esta espécie (Fig. 1), mas apenas comentar algumas variações, como por exemplo a disposição dos olhos que, em geral são bem separados, podendo estar mais aproximados e muito raramente contíguos. Em todo material examinado somente um exemplar foi observado com esta última característica.

Também a coloração dos élitros 

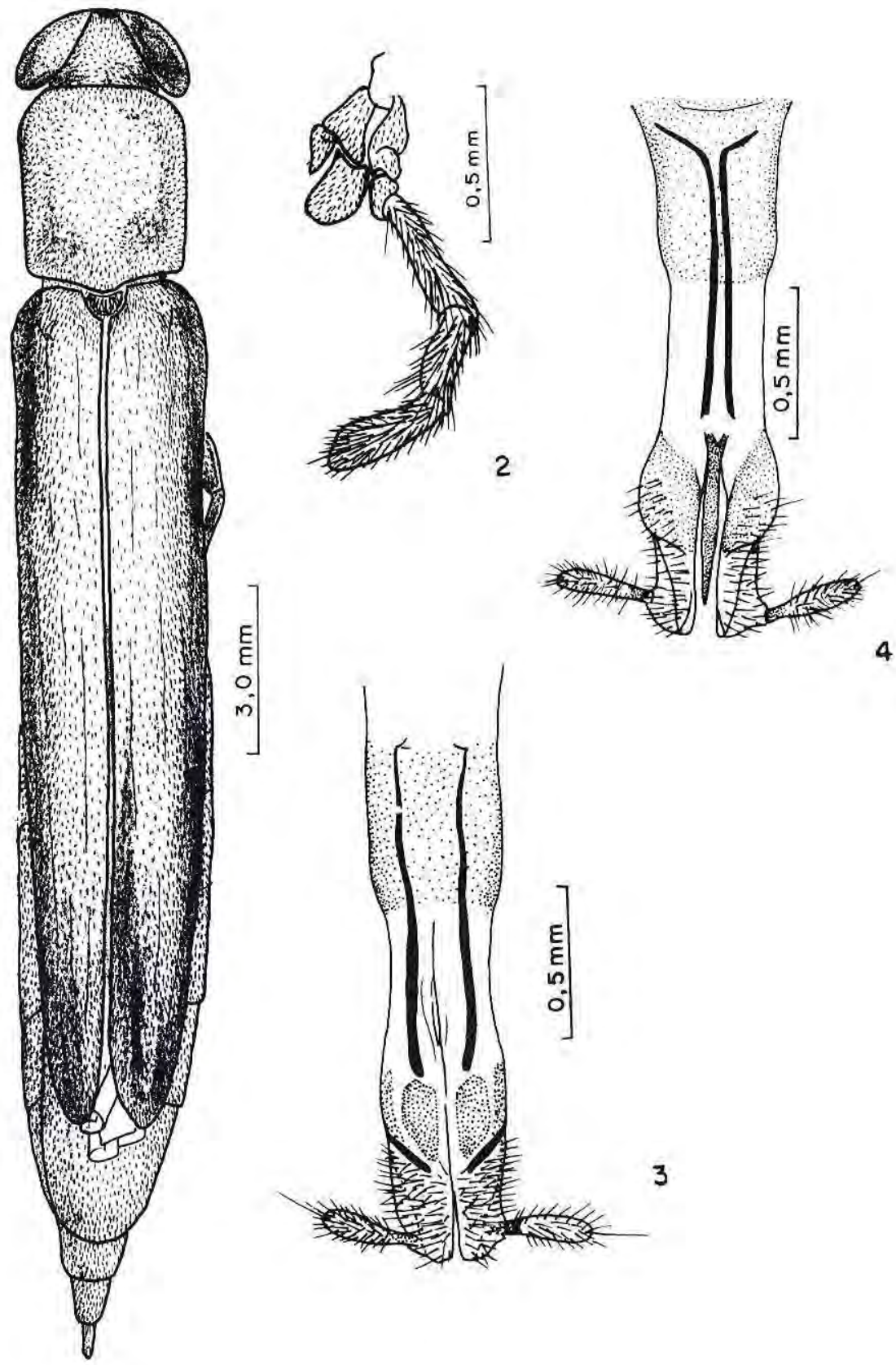

Figuras 1 a 4. Melittomma brasiliense. Fêmea: 1, Vista dorsal; 2, Maxila; 3, Genitália em vista dorsal; 4, Genitália em vista ventral. 
pode variar de amarelo-palha a amarelo-escuro, podendo ou não aparecer obscurecido nas regiões basal e lateral.

Nas maxilas (Fig. 2), a lacínia é conspícua e menor que a gálea, em ambos os sexos, embora no trabalho de Lane (1955) a ilustração defina a presença da mala, na fềmea.

Comentários: Wheeler (1986) em sua revisão mundial mostra ilustrações apropriadas da terminália masculina e menos elucidativas da feminina e, devido a isso, são reapresentados esquemas destas peças aqui para que possam ser comparados com a outra espécie descrita neste trabalho (Figs. 3 e 4).

As espécies neotropicais do gênero Melittomma foram estudadas por Lane (1955), que considerou sinônimos de $M$. brasiliense as espécies Hylecoetus brasiliensis Laporte, $H$. angustus Taschenb., Melittomma casteneum Murray. Também deixou a suposição de que $M$. lateritium (Fairmaire), $M$. marginellum Schenkling, $M$. africanum (Thomson) poderiam ser sinônimos de $M$. brasiliense. Desde então não há registro de novas revisões taxonômicas para o grupo, a não ser o trabalho de Wheeler (1986) onde são analisadas as relações filéticas dos gêneros de Lymexylidae,

Material examinado: MÉXICO. Veracruz: Cordoba, v.1988 (Fred Knab), 1 우 (NHM); Fortin, v.1963 (M.W.MacFadden), 1 ㅇ (NHM); Los Tuxtlas, Las Cabañas, 3-5.v.1981 (C.M. \& O.S.Flint, Jr.), 2 우 (NHM); Chiapas: 1919 (L.Hotzen), 1 우
(NHM), GUATEMALA. Cayuga, iv.1915 (Wm.Schaus), 3 우 (NHM); 1915 (Wm. Schaus), 1 ㅇ (NHM). COSTA RICA. Santa Clara, Fazenda Hamburg, 25.x.1935 (sem coletor), 1 우 (NHM); Puntarenas, iii.1973 (R.Silberglied), 1 क (NHM); Rio Sixola, sem data (sem coletor), 1 if (NHM); xi.1921, 1 우 (NHM); 10.vi.1923, 1 우 (NHM); 15.xi.1923, 1 우 (NHM); 05.v.1924, 1 우 (NHM); 15.vii.1924, 1 우 (NHM); 01.x.1924; 29.x.1924, 1 우 (NHM); 01.i.1931, 1 우 (NHM); 10.i.1931, 1 우 (NHM); 01.x.1932, 1 우 (NHM); 30.ix.1932, 1 우 (NHM); 20.iii.1934, 1 우 (NHM); v.1934, 1 우 (NHM); 28.xi.1935, 1 우 (NHM); 15.v.1936, 1 우 (NHM); 08.v.1928, 1 우 (NHM); 26.x.1929, 1 우 (NHM); 05.ix.1934, 1 우 (NHM); 24.viii.1936, 1 우 (NHM), todos coletados por F.Nevermann; Turrialba, 07-10.iii.1965 (S.S. \& W. D. Duckworth), 1 ㅇ (NHM); 13-17.iii.1965 (S.S. \& W.D.Duckworth), 1 우 (NHM); 15 19.vii.1965 (Spangler), 1 ㅇ (NHM). PANAMÁ. Zona do Canal: Barro Colorado, vi.1940 (Zetk), $1 \sigma^{x}$ (NHM); 29.iii.1978 (Silberglied/Aiello), 10 (NHM);18-28.iv.1964 (W.D. \& S. S. Duckworth), 2 우 우 (NHM); 0109.v.1964 (W.D. \& S.S.Duckworth), 1 ㅇ (NHM); 20-23.v.1964 (W.D. \& S. S. Duckworth), 5 우우 (NHM);1017.v.1964 (W.D. \& S.S.Duckworth), 21 우우 (NHM); 25-28.iii.1965 (S.S. \& W.D.Duckworth), 1 우 (NHM); 0608.xii.1971 (T.L. \& L.J. Erwin), 1 우 (NHM); 17-27.v.1972 (T.L.Erwin \& L.J.Erwin), 2 우 (NHM); Porto Bello, 21.iv.1912 (A.Busck), 2우우 (NHM); Gatun Lake, 08.v.1923 (R. C. 
Schannon), $10^{*}$ (NHM); Cerro Campana, Nr. Chica, 02-05.iv.1965 (S.S. \& W.D.Duckworth), 2 우우 (NHM). TRINIDAD. Simla, 0510.ii.1966 (sem coletor), 1 우 (NHM). VENEZUELA. Território Federal do Amazonas: Cerro de la Neblina, (Basecamp), 20-29.ii.1984 (D.Davis \& T.McCabe), 3 우 우 (NHM); id., 0110.iii.1984 (D.Davis \& T. McCabe), 6 우 (NHM); Aragua, Rancho Grande, 22-31.vii.1967 (R.W.Poole), $20^{x} 0^{x}, 1$ 우 (NHM); 05.viii.1968 (J.Maldonado), 1 ㅇ (NHM); Barinas, Rio Caparo, 03-15.ii.1978 (J.B.Heppner), 1 ㅇ (NHM); Barinitas, 23.ii.1969 (P. \& P.Spangler), 1 우 (NHM). GUIANA FRANCESA. St.Jean, sem data (sem coletor), 1 우 (NHM). COLÔMBIA. Tablones Valle, Finca La Florida, 07.i.1959 (J.T.G. Clarke), 2 우 (NHM). EQUADOR. Los Rios, Est. Biol. Palenque, 15.ii.1979 (Gene Skhupp), 1 \% (NHM). PERU. Sinchona, 20.iv. 1944 (J.G.Sander), 1 i (NHM); Tingo Maria, 13.ix.1956 (Gregoire), 1 우 (NHM); Madre de Dios, Manú, Erika, 0406.ix.1988 (O.Flint \& N. Adams), 1 우 (NHM). PARAGUAI. S.Bernardino, xi.1920 (K.Friebrig), 1 우 (NHM). BRASIL. Amazonas: Manaus, (Reserva Ducke), 22.xii.1976 (B.C.Ratcliffe), 1 우 (INPA); (Parque das Laranjeiras), 02.vii.1981 (J.Arias), 1 i (INPA); Rodovia BR 174, Km 130, 16.xi.1977 (B.C. Ratcliffe), $10^{x}$ (INPA); Rodovia BR $174 \mathrm{Km} \mathrm{61,} \mathrm{ZF-}$ 2, 25-26.ix.1984 (J.V.da Silva), 1 ㅇ (FUA); 14-15.iii.1988 (J.V.da Silva), 1 우 (FUA); 15-16.ix.1988 (J.V.da Silva), 1 우 (FUA); 05-06.xii.1988
(J.V.da Silva), 19 (FUA); 0607.xii.1988 (J.V.da Silva), 1 ㅇ (FUA); Rio Solimões, (Igarapé Sta. Rita), 18.ix.1961 (Eduardo), 1 우 (INPA); Pará: Acará, (Ilha do Combu), 25.x.1980 (R.B.Neto), 1 \% (MPEG); Serra Norte, (Manganês), 17.xi.1985 (F.F.Ramos), 1 ㅇ (MPEG); Rondônia: Ouro Preto do Oeste, xii.1963 (B.Silva), 1 ㅇ (M.N.); Mato Grosso: Rio Branco, xii.1984 (Magno \& Alvarenga), 1 ㅇ (M.N.); Espirito Santo: Barra do São Francisco (Córrego Itá), xi.1958 (W.Zikan), 3 우우 (MZUSP); Ribeirão do Engano, (Vale do Itaúna), 09.x.1942 (Trav. \& Santos), 2 우 (M.N.); Conceição da Barra, 29.xi.1969 (C.T. \& C.Elias), 1 우 (UFPR); Minas Gerais: Viçosa, xi.1930 (E.J.Hambleton), 1 ㅇ (NHM); Rio de Janeiro: Rio de Janeiro (Represa Rio Grande), 08.ix.1960 (F.M.Oliveira), 2 우 (M.N.); Angra dos Reis, iv.1931 (L.T.), 1 우 (MZUSP); (Jussaral), ix.1935 (D.Mendes), 2 우우 (M.N.); Fazenda Japuhyba, ix.1945 (L. Travassos), 1 우 (MZUSP); Rio de Janeiro, (Floresta da Tijuca), i.1961 (C.A.Campos Seabra), 1 우 (UFPR); 07.i.1957 (C.Seabra), 1 우 (M.N.); (Instituto Oswaldo Cruz), 18-29.x.1938 (sem coletor), 1 우 (MZUSP); Santa Catarina: Jaraguá, xi.1938 (A.Maller), 1 우 (M.N.); Seara (Nova Teutônia), xii.1970, 5MM, 1 우 (NHM); i.1971, 10 \% (NHM); x.1971, 1 우 (NHM); ix.1972, $20^{x} 0^{x}$ (NHM); x.1972, $20^{x} 0^{x}, 4$ 우 우 (NHM); xii.1972, $20^{x} \sigma^{x}, 1$ 우 (NHM); iii.1973, 1 우 (NHM); iv.1973, $10^{*}$ (NHM); xii.1973, 1 ( $(\mathrm{NHM})$; ix. 1975, 1 으 (NHM); xi.1975, 1 우 (UFPR); xi $1975,10^{*}$ (NHM); xii.1975, $10^{x}$ 
(NHM); x.1980, 4 우 (UFPR) todos coletados por F.Plaumann; Corupá, xii.1966 (A.Maller), 1 ㅇ (UFPR); Rio Grande do Sul: São Leopoldo, 12.xii.1983 (C.J.Becker) 10 (FZRS).

\section{Melittomma nana sp.n.}

Macho: corpo alongado, recoberto por pequenas cerdas, coloração geral amarelo palha e castanho avermelhado, comprimento variando entre 5 e $13 \mathrm{~mm}$ (Fig. 5).

Cabeça (Fig. 6) hipognata globosa, constricta posteriormente. Olhos grandes, contíguos em toda margem interna e envolvendo inteiramente a gena e a fronte. Clípeo pequeno, transverso. Labro subtriangular com cerdas abundantes recobrindo a superfície. Epifaringe com carena longitudinal. Mandíbulas (Fig. 7) simétricas, com ápice tridentado e cerdas na face externa. Maxilas (Fig. 8) apresentando ápice arredondado e totalmente recoberta por cerdas fortes; lacínia trianguliforme e de comprimento subigual ao da gálea; palpos maxilares com cinco segmentos, o primeiro pequeno, subcônico e recoberto por cerdas, o segundo semi-esférico e três vezes o tamanho do primeiro, terceiro segmento semi-esférico formando uma bainha que envolve o quarto segmento que, por sua vez, é alongado e em formato de bastão; quinto segmento aproximadamente cinco vezes mais longo que o quarto segmento, possuindo flabelos longos e compostos, recobertos por cerdas. Mento (Fig. 9) recoberto por cerdas longas dispersas na superfície; palpos labiais com três segmentos, o primeiro medindo cerca da metade do segundo e o terceiro claviforme; hipofaringe (Fig. 10) hialina, bilobada, lembrando um "Y", glabra externamente e internamente com cerdas fortes, na área côncava da região distal entre os lobos laterais. Antenas (Fig. 11) com onze segmentos e recoberta por cerdas de tamanhos variados, apresentando flabelos curtos nos segmentos quatro a dez, que não ultrapassam o comprimento dos segmentos antenais. Tórax: Protórax (Fig. 12) mais longo que largo, em forma de cela na região anterior; manchas presentes ou não nas laterais e na bordadura posterior; borda anterior fortemente arredondada, quase oblíqua próximo aos ângulos anteriores, estes, obtusos e arredondados. Gibosidade na região posterior e, carenas pronunciadas nas bordas laterais. Prosterno subquadrangular com bordadura posterior arredondada. Élitros recobertos por cerdas curtas; coloração amarelo palha podendo apresentar ou não manchas escuras na região umeral, que se estendem até aproximadamente $2 / 3$ do comprimento total. Pernas alongadas e delgadas. Perna I (Fig, 13) com um espinho apical na tíbia; tarso com cinco segmentos; o primeiro de comprimento semelhante à soma do segundo e terceiro; quarto subigual em comprimento ao terceiro; quinto cerca de duas vezes o comprimento do quarto. Perna II (Fig. 14) apresentando dois pequenos espinhos no ápice tibial; os três primeiros segmentos tarsais como na perna I; quarto segmento pequeno medindo cerca da metade do 


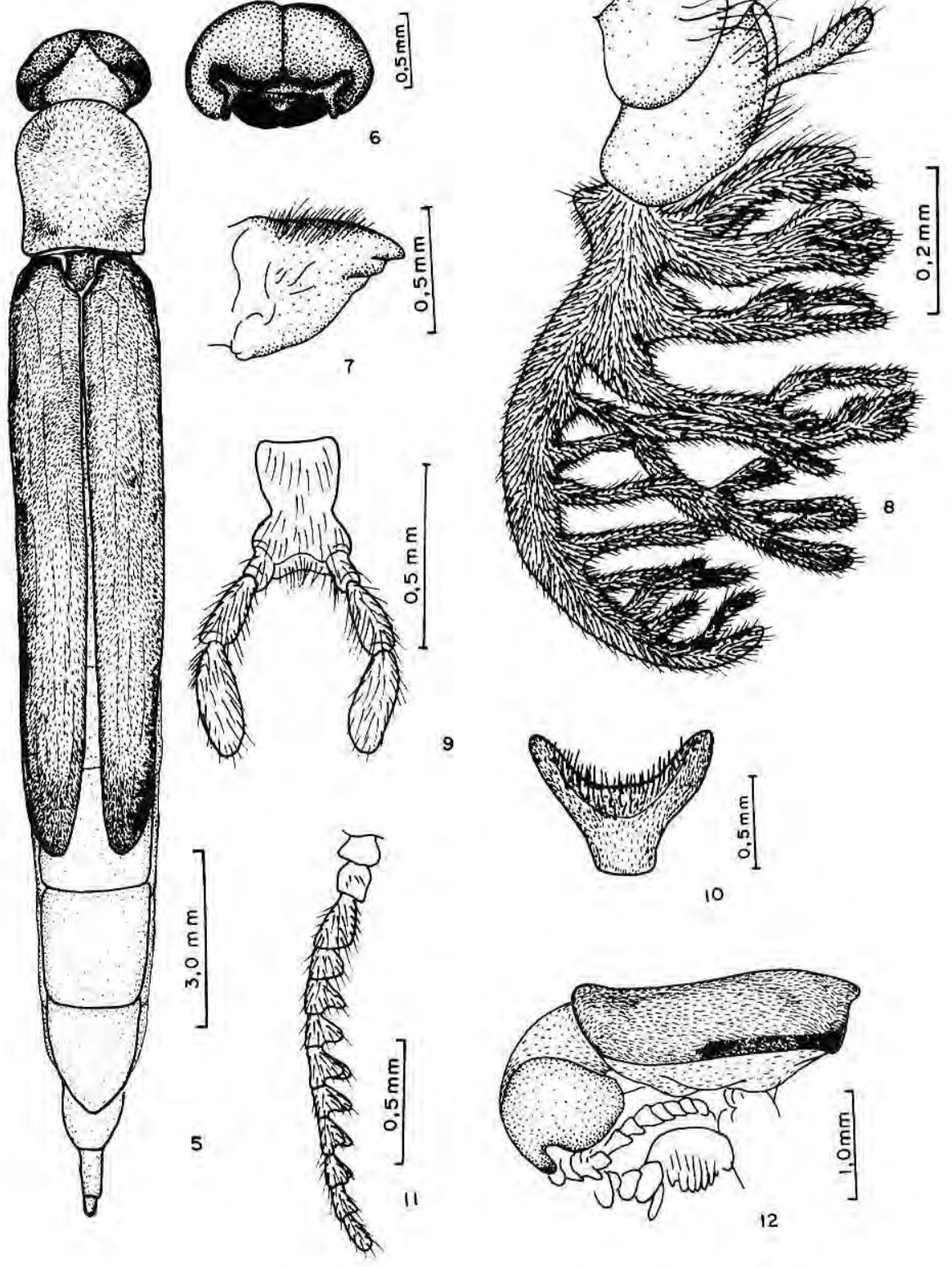

Figuras 5 a 12. Melittomma nana sp. n. Macho: 5 , Vista dorsal; 6 , Cabeça em vista frontal; 7 , Mandibula em vista lateral; 8, Maxilar; 9, Labio; 10, Hipofaringe; 11, Antena; 12, Protórax e cabeça em vista lateral. 

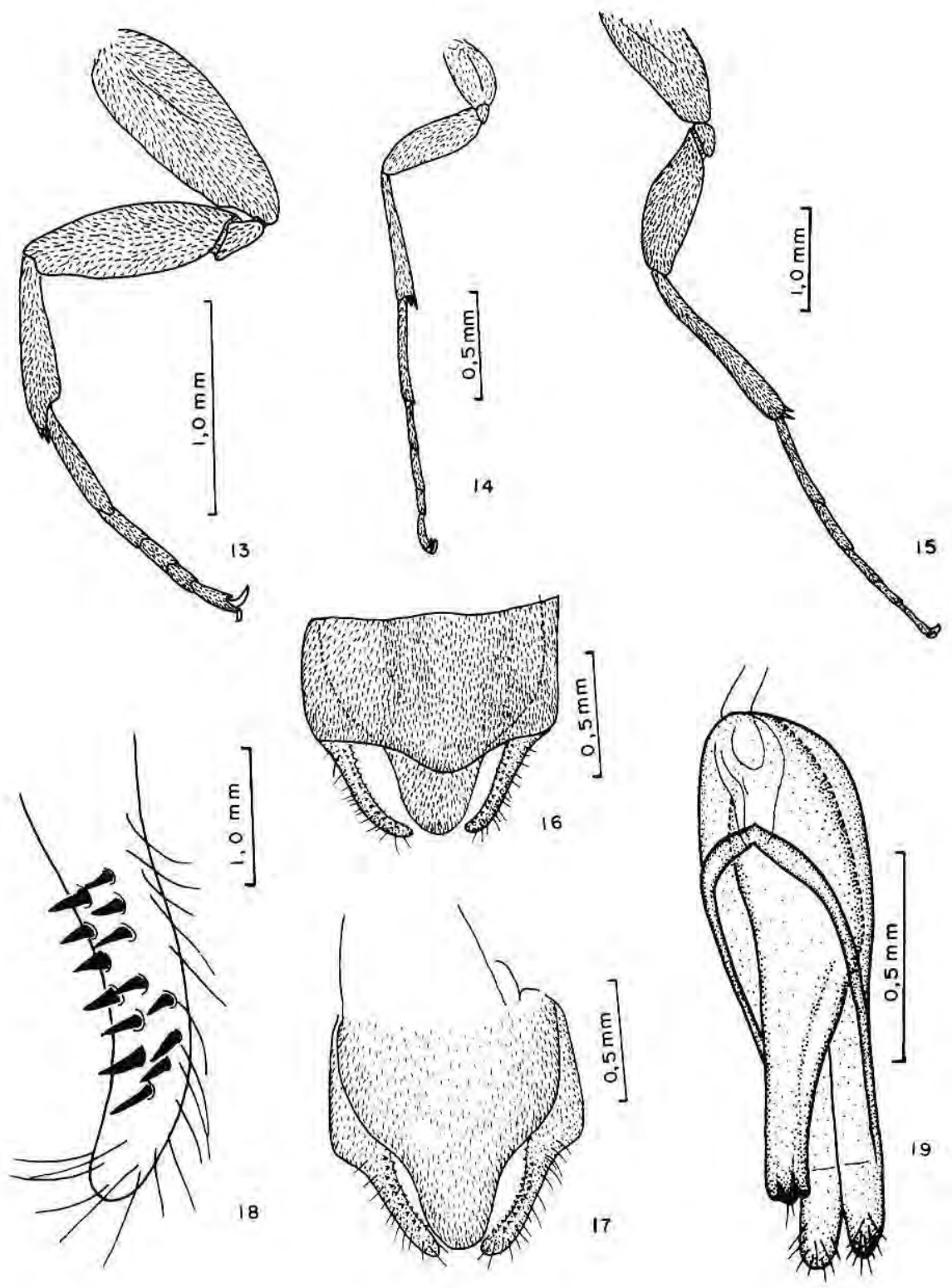

Figuras 13 a 19. Melittomma nana sp. n. Macho; 13, Perna anterior; 14, Perna média; 15, Perna posterior macho; 16, Paratergitos do nono segmento abdominal em vista ventral; 17 , Paratergitos do nono segmento abdominal em vista dorsal; 18, Detalhe do ápice dos paratergitos com os dentes da face interna; 19, Edeago em vista dorsal. 
quinto segmento. Perna III (Fig. 15) apresentando dois espinhos no ápice tibial; primeiro segmento tarsal de comprimento equivalente à soma dos três últimos segmentos; terceiro de comprimento semelhante ao dobro do quarto segmento.

Abdome: com 5 esternitos visíveis dorsalmente; genitália apresentando os paratergitos (Figs. 1618) abruptamente afilados da metade apical para o ápice, e com dentes pequenos na face interna. Face dorsal (Fig. 17) em formato subtriangular com ápice arredondado. Edeago (Fig. 19) exibindo o lobo médio com ápice tetralobado, ápice dos lobos laterais arredondados e com cerdas.

Fêmea: muito semelhante ao macho. Palpos maxilares (Fig. 20) com quatro segmentos; primeiro curto; segundo e quarto semelhantes em comprimento; terceiro com cerca de duas vezes o comprimento do primeiro.

Abdome: genitália (Figs. 21, 22) de formato geral subcilíndrico, valvifero hialino apresentando uma mancha esclerotinizada na região mediana lateral; possui quatro processos valviferais, dois dorsais e dois ventrais; com comprimento subigual ao do valvifero. Primeira dobra coxital quase inconspícua; coxito basal esclerotinizado e recoberto por cerdas fortes em sua região dorsal, face ventral com a porção distal subtriangular; segunda dobra coxital muito evidente; coxito distal bilobado hialino recoberto por cerdas fortes e mais longas que as do coxito basal. Estilos em forma de bastão recoberto por cerdas fortes, semelhantes às do coxito distal e com uma cerda apical mais longa que as demais. Bolsa de fungos elipsóide estendendo-se da região mediana do coxito basal até o ápice do coxito distal.

Material examinado: Holótipo ox, BRASIL. Amazonas: Manaus, AM010 Km 26 Reserva Ducke, 07.iii.1978 (Jorge Arias), INPA. Parátipos: idem, 07.ii.1978 (J. Arias), 1 우 (INPA); 04.iv.1978 (J.Arias \& N.Penny), 1 ㅇ (INPA); 03.i.1978 (J. Arias), $10^{*}$ (INPA); 13.xii.1977 (J.Arias), $10^{x}$ (INPA); Rondonia: Ariquemes (Rio Ji-Paraná), 26.x.1986 (J.A.Rafael), 1 우 (INPA); 28.x.1986 (J.A.Rafael), 1 우 (INPA); Vilhena, xi.1987 (O.Roppa \& P.Magno), $10^{*}$ (M.N.); Mato Grosso: Chapada dos Guimarães, 01.xii.1983 [Exp. Dep. Zool. UFPR (POLONOROESTE)], $10^{*}$ (UFPR); 27.xi.1983 [Exp. Dep. Zool. UFPR (POLONOROESTE)], $10^{*}$ (UFPR); Espirito Santo: Barra do São Francisco (Córrego Itá), x.1954 (W. Zikán), $10^{*}$ (MZUSP), 3 우우 (M.N.); Rio de Janeiro: Angra, i.1935 (Dario Mendes), $10^{*}$ (MZUSP); Paraná: Fóz do Iguaçu, 07.xii.1966 (UFPR), $20^{x} 0^{x}$ (UFPR); Santa Catarina: Seara (Nova Teutônia), x.1944 (Fritz Plaumann), $10^{\prime \prime}$ (MZUSP). MÉXICO. Veracruz: Los Tuxtlas (Las Cabañas), 08-15.v.1981 (C.M. \& O.S. Flint, Jr.), $10^{\star}$ (NHM). GUATEMALA. Alta Vera Paz: Cacao (Trece Aguas), (sem-data) (Barber \& Schwarz), $10^{\top}$ (NHM). COSTA RICA. (sem data) (sem coletor), 1 우 (NHM); iii.1935 (F.Nevermann), $10^{*}$ (NHM); 25.ix.1935 (F.Nevermann), 10 (NHM); Turrialba, 07-10.iii.1965 (S.S. \& W.D.Duckworth), $1 \sigma^{*}$ (NMH); 15.iii.1923 (F.Nevermann), $10^{\top}$ (NHM); 
27.i.1924 (F.Nevermann), $10^{x}$ (NHM); 25.xi.1937 (F.Nevermann), $10^{*}$ (NHM). PANAMÁ. Zona do Canal: Barro Colorado, ix-x.1940 (Jas Zetek), $10^{\star}$ (NHM); 26.xii.1940 (K.W.Cooper), $10^{\pi}$ (NHM); v.1941 (Jas Zetek), $10^{\pi}$ (NHM); iv.1941 (Jas Zetk), $10^{\pi}$ (NHM); $x$-xi.1941 (sem coletor), $20^{*} \sigma^{x}$ (NHM); iv-v.1942 (Jas Zetek), $10^{7}$ (NHM); 23.vi.1948 (J.E.Graf), $10^{\text {t }}$ (NHM); 01-09.v.1964 (W.D. \& S.S.Duckworth), $10^{x}, 1$ ( (NHM); $10-$ 17.v.1964 (W.D. \& S.S.Duckworth), $20^{x} 0^{x}, 4$ 우 우 (NHM); 02.vii. 1974 (T.L.Erwin \& D.R. Whitehead), $10^{*}$ (NHM); San José: Pearl Is., viii.1944 (Morrison), $10^{x}$ (NHM); Code: El Valle, 22.iv, 1965 (S.S \& W.D.Duckworth), 10 (NHM).

Etimologia: nana $=$ pequena, refere-se ao comprimento dos exemplares da espécie.

Discussão: $M$. nana $\mathrm{sp}, \mathrm{n}$. difere de $M$. brasiliense pelo $3^{\circ}$ segmento do palpo labial mais curto, pelos olhos invariavelmente contíguos, pela forma do mento mais alargada, pela gálea de comprimento semelhante ao da lacínia, pelo pronoto mais longo que largo apresentando margem anterior arredondada. Na genitália feminina, a bolsa de fungos é maior, o coxito basal é mais arredondado, o coxito distal alargado, o estilo tem forma de bastão inteiramente hialino (clavado e esclerotinizado na base em $M$. brasiliense), com cerdas longas e fortes recobrindo também a região coxital.

Quanto à genitália masculina, difere de $M$. brasiliense pelo formato do paratergito que apresenta quantidade menor de dentes surgindo unicamente na face interna; pelo edeago que apresenta o lobo médio com ápice tetralobado.

\section{Melittomma brunnea sp.n.}

Corpo alongado delgado, densamente recoberto por cerdas curtas e brilhantes. Coloração geral castanho; comprimento $12 \mathrm{~mm}$.

Cabeça (Fig. 23) hipognata, globosa, apresentando constrição posterior; fosseta epicranial presente. Olhos grandes, contíguos, envolvendo inteiramente a gena e a fronte. Clipeo pequeno, transverso; labro subtriangular com cerdas abundantes de coloração amarelo brilhante ou douradas. Epifaringe com carena longitudinal. Mandíbulas simétricas, com o ápice tridentado e cerdas na face externa. Palpos maxilares e labiais semelhantes aos de $M$. nana.

Tórax: com o pronoto tão longo quanto largo; bordadura anterior ligeiramente côncava, ângulos anteriores arredondados e obtusos; ângulos posteriores protraídos e algo dirigidos para cima; bordas laterais sinuosas e carenadas. Escutelo subquadrangular com a borda posterior arredondada. Élitros alongados cobrindo quase inteiramente $o$ abdome. Perna I (Fig. 24) sem espinho apical tibial; primeiro segmento tarsal aproximadamente duas vezes o comprimento do segundo; segundo equivalente à soma do terceiro $\mathrm{e}$ quarto; terceiro, quarto e quinto segmentos subiguais. Perna II (Fig. 25) 


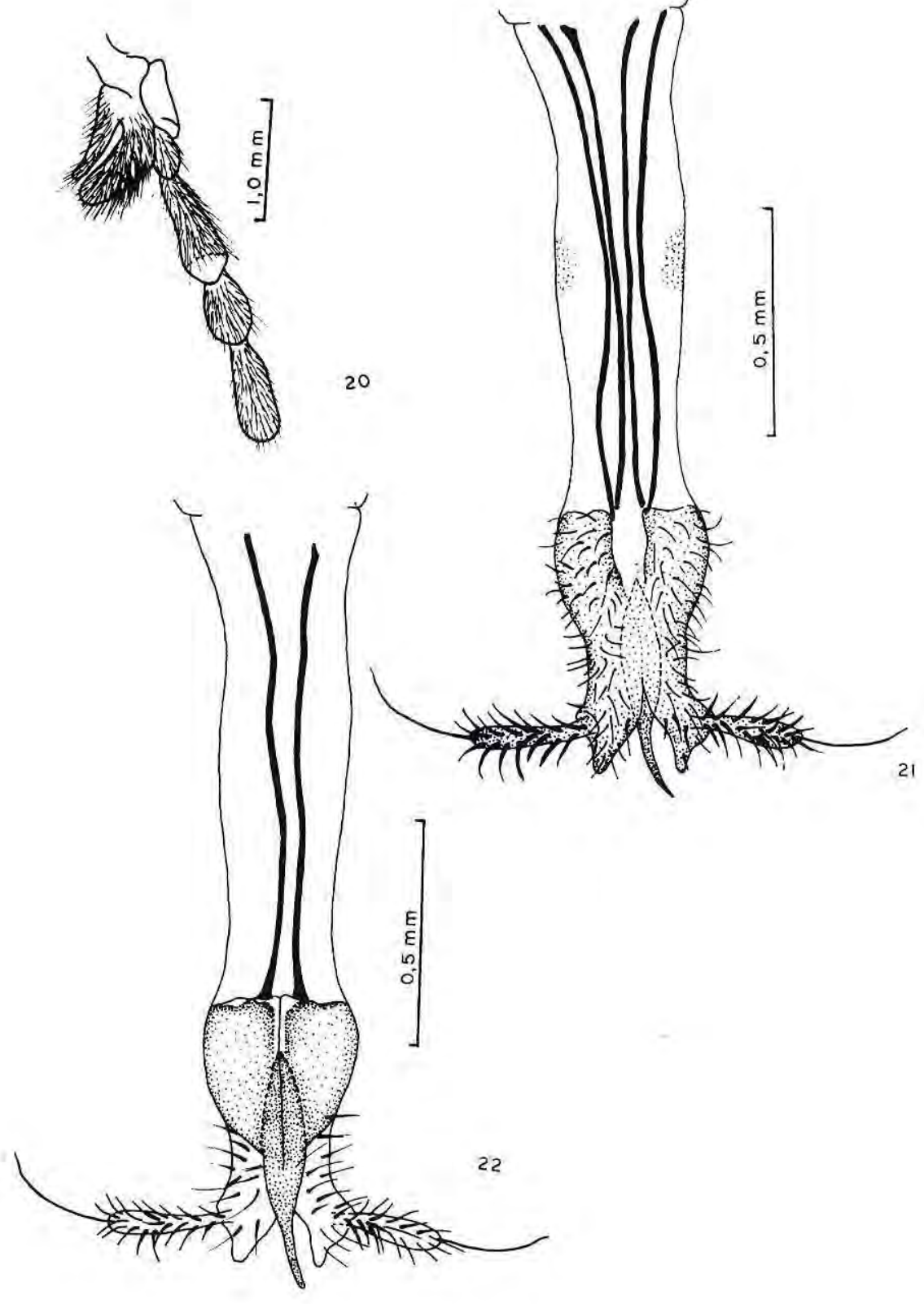

Figuras 20 a 22. Melittomma nana sp.n. Fêmea: 20, Maxila esquerda; 21, Genitália em vista dorsal; 22 , Genitália em vista ventral. 
armada com espinho apical tibial; primeiro segmento tarsal de comprimento semelhante a soma do segundo e terceiro; segundo e terceiro subiguais no comprimento; terceiro, quarto e quinto segmentos subiguais. Perna III (Fig. 26) com espinho apical tibial; primeiro segmento tarsal cerca de duas vezes o comprimento do segundo; segundo semelhante à soma do comprimento do terceiro e do quarto.

Abdome: com cinco esternitos visíveis, último segmento com ápice arredondado. Genitália masculina apresentando os paratergitos do nono segmento abdominal recurvados para dentro e amplamente dilatados nas extremidades, em forma de espátula (Figs. 27, 28). Borda interna da extremidade apical dos paratergitos (Fig. 29) ornamentada com cerdas e séries de dentes pequenos, quase vestigiais. Edeago possuindo lobo médio com ápice dilatado e esférico onde aparece uma fina porosidade recobrindo toda a região apical. Lobos laterais com o ápice fundido, arredondado e cerdoso (Figs. 30, 31).

Material examinado: Holótipo ", BRASIL. Rondônia: Ariquemes, Rio Ji-Paraná, 28.x.1986 (J.A.Rafael), INPA.

Etimologia: brunnea = castanho, refere-se à coloração geral do inseto, muito característica.

Discussão. Indivíduos de Lymexylidae são geralmente difíceis de capturar e consequentemente raros nas coleções. Também não é prática dos autores deste trabalho descrever espécies novas sem séries de indivíduos que possibilitem uma discussão segura dos caracteres que identificam o táxon. Todavia, dada a raridade deste grupo, justifica-se a descrição desta nova espécie baseada em apenas um exemplar, além de que, os caracteres observados garantem uma definição tácita da espécie. $M$. brunnea difere das demais espécies pela sua coloração castanha muito evidente, e principalmente pela genitália masculina que apresenta os paratergitos muito dilatados tendo a borda interna com uma série característica de pequenos dentes vestigiais. O edeago é singular, apresentando o ápice também dilatado e esférico, além de que os lobos laterais apresentam-se fundidos.

\section{Melittomma panamensis sp. $\mathbf{n}$.}

Macho de coloração geral castanho escura com farta cerdosidade amarelada recobrindo inteiramente o corpo. Olhos contiguos envolvendo toda área genal e frontal, apresentando emarginação próxima à base das antenas. Comprimento 13,2 mm.

Cabeça (Fig. 32) hipognata com clípeo pequeno transverso e muito cerdoso. Mandíbulas simétricas e com o ápice tridentado. Maxilas (Fig. 33) apresentando gálea ampla, densamente recoberta por cerdas longas e fortes, com ápice subcônico; lacínia com 1/3 da largura da gálea, comprimento menor e da mesma forma densamente cerdosa. Palpos maxilares (Fig. 33) 

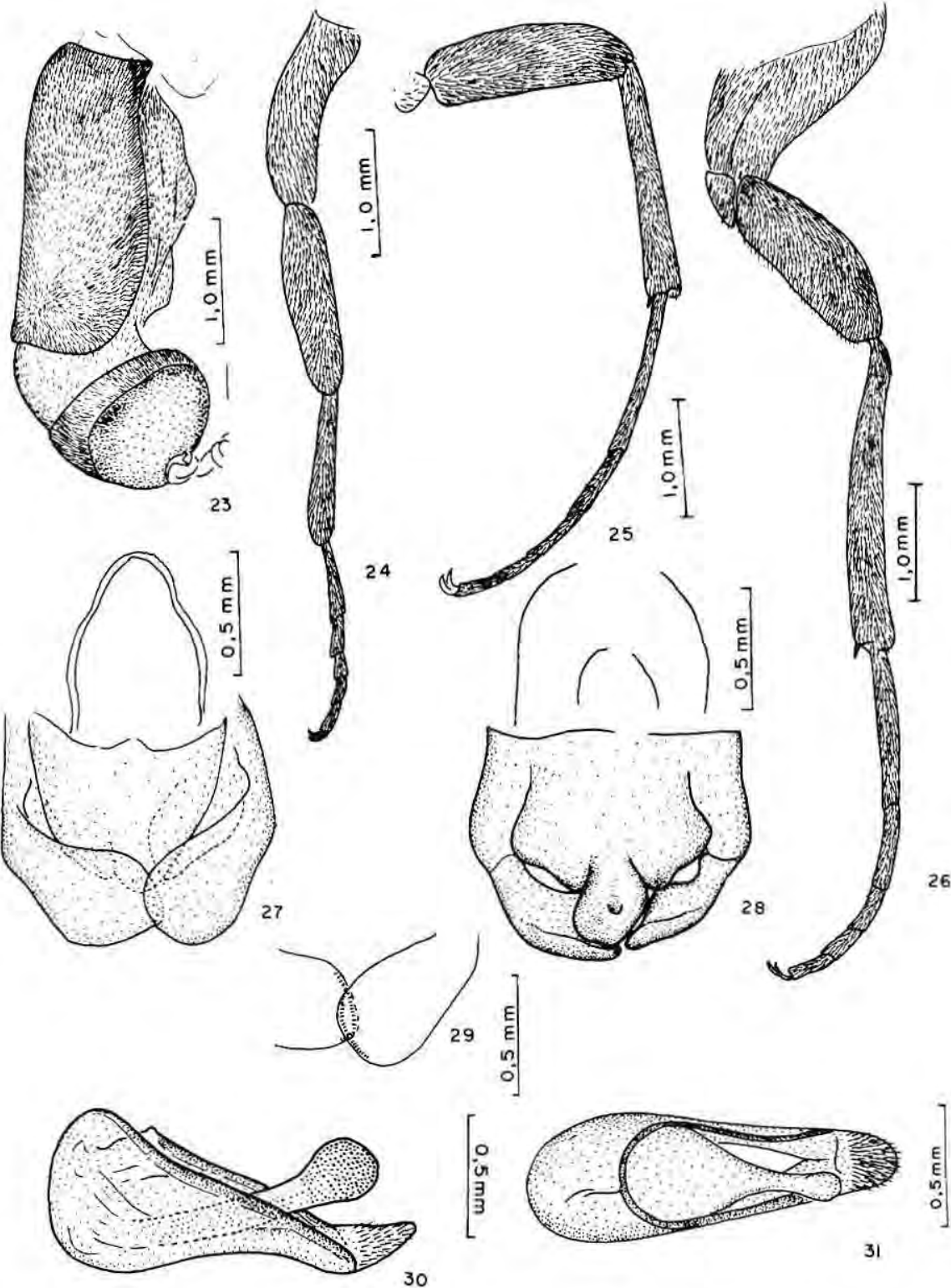

30

Figuras 23 a 31. Melittomma brunnea sp.n. Macho: 23, Cabeça e pronoto em vísta lateral; 24 , Perna anterior; 25; Perna média; 26, Perna posterior; 27, Genitália em vista dorsal; 28, Genitália em vista ventral; 29 , Borda interna do ápice do paratergito do nono segmento abdominal; 30 , Edeago em vista lateral; 31, Edeago em vista dorsal. 
apresentando o primeiro segmento pequeno e subcilíndrico; segundo segmento globoso e com cerdas longas e pouco densas na metade proximal; terceiro segmento maior e de formato semelhante ao segundo; quarto segmento formando um longo e delgado apêndice com a extremidade fracamente clavada de onde saem cerdas curtas e fortes; quinto segmento subdividido em três ramos que, por sua vez, possuem outros ramos menores e compostos. Hipofaringe (Fig. 34) carenada e bilobada. Palpos labiais (Fig. 35) possuindo três segmentos, sendo o primeiro pequeno e subcilíndrico, o segundo subcônico com cerca de três vezes o comprimento do primeiro e o terceiro segmento maior que o segundo e de formato fusiforme.

Tórax: (Fig. 32) com o pronoto mais longo que largo, apresentando borda anterior reta e ângulos anteriores arredondados; bordas laterais aguçadas e ângulos posteriores agudos. Perna I (Fig. 36) menor que as demais com o primeiro segmento tarsal medindo aproximadamente a soma do comprimento dos dois posteriores. Perna II (Fig. 37) com o primeiro segmento muito longo, o segundo medindo metade do primeiro e os três apicais subiguais em comprimento. Perna III (Fig. 38) armada com forte espinho apical tibial e semelhante à anterior.

Abdome: com cinco esternitos visíveis. Genitália masculina apresentando os paratergitos (Fig. 39) largos e com o ápice rombo digitiforme e projetado para frente; o terço apical (Fig. 40) está recoberto por fileiras de espinhos curtos, fortes, esclerotinizados e de coloração escura; os dois terços proximais estão revestidos por cerdas esparsas, longas e delgadas. Edeago (Fig. 41) com o ápice do lobo médio arredondado e revestido por fina pontuação; lobos laterais (Fig. 42) formando uma aba convexa bilobada no ápice, recobrindo inteiramente o ápice do lobo médio, sendo ornamentada por cerdas finas e delgadas.

Discussão. $M$. panamensis aproxima-se de $M$. brunnea, considerando-se as semelhanças das genitálias dos machos. No entanto, $M$. panamensis difere de $M$. brunnea pela anatomia dos paratergitos do nono segmento abdominal que apresentam dentes fortes na região proximal do ápice, além de possuírem densa cerdosidade; pela região mediana da borda distal do nono segmento abdominal que se apresenta afilada, digitiforme; e pelos lobos laterais do edeago que formam uma aba característica com o ápice bilobado.

Material examinado: Holótipo ", PANAMÁ. Zona do Canal: Ilha Barro Colorado, 28.vi.1973 (T.Erwin \& Havel) NHM.

\section{BIBLIOGRAFIA CITADA}

Crowson, R.A. 1981. Biology of Coleoptera. London, Academic, 802 p.

Fairmaire, L. 1887. Coléoptéres nouveaux ou peu connus du Musée de Leyden. Notes 


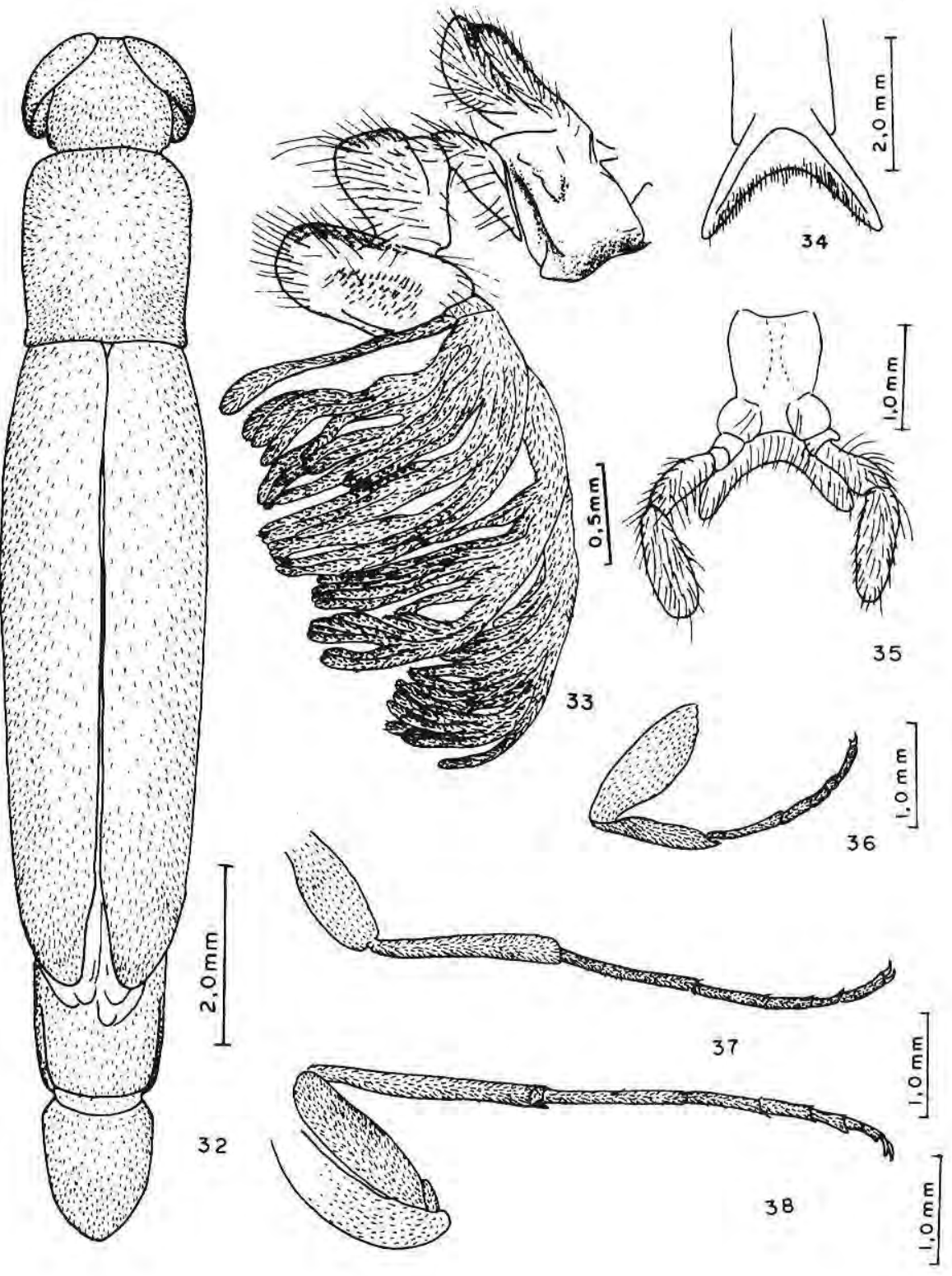

Figuras 32 a 38. Melittomma panamensis sp.n. Macho: 32, Vista dorsal; 33, Maxila e palpo maxilar; 34, Hipofaringe; 35, Palpos labiais; 36, Perna anterior; 37, Perna média; 38, Perna posterior. 

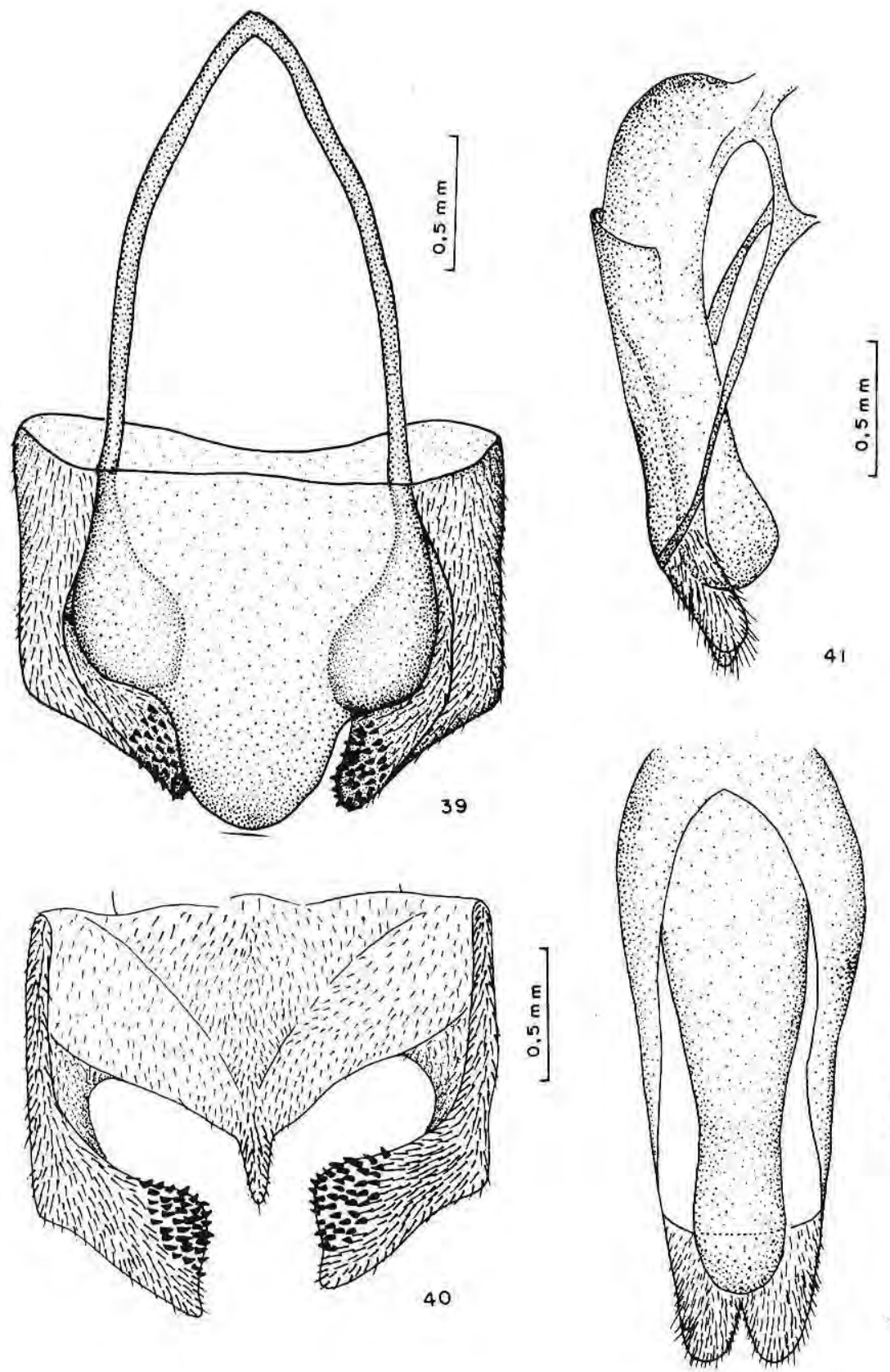

$\left.\begin{array}{c}E \\ E \\ 0 \\ 0\end{array}\right]$

42

Figuras 39 a 42. Melittomma panamensis sp.n. Macho: 39, Genitália em vista dorsal; 40, Genitália em vista ventral; 41, Edeago em vista lateral; 42, Edeago em vista dorsal. 
Leyden Mus. 9: 145-162.

Gorhan, H. S. 1881, Insecta, Coleoptera, Lycidae, Lampyridae, Telephoridae, Lymexylonidae, Melyridae. In: F.D. Goldman \& O. Salvin (Eds)., Biologia Centrali Americana Zoology 3(2): 25-112.

Kurosawa, Y. 1985. Revisional notes on the family Lymexylonidae (Coleoptera) in Eastern and Southeastern Asia. Bull. Natl. Sci. Mus., Tokyo. Ser. A, 11: 109-119.

Lane, F. 1955. Novos gêneros e espécies de Coleoptera Lymexylonidae e notas sobre Melittomma Murray, 1867. Papeis Avulsos do Departamento de Zoologia, Secretaria de Agricultura., S. Paulo, 12: 141-163.

Lawrence, J.F e A. F. Newton Jr, 1982. Evolution and Classification of Beetles. Ann. Rev. Ecol. Syst. 13: 261-290.

Lawrence, J.F. e A F. Newton Jr. 1995. Families and subfamilies of Coleoptera (with selected genera, notes, references and data on family-group names), p.779-1006. In: J. Pakaluk \& S. A. Slipinski (Eds.) Biology, Phylogeny, and Classification of Coleoptera. Papers Celebrating the $80^{\text {th }}$ Birthday of Roy A. Crowson. Warszawa, Muzeum i Instytut Zoologii PAN, (Varsóvia) Warszawa 1006 p.

Leng, C.W. 1920. Catalogue of the Coleoptera of America, North of Mexico. Mt. Vernon, Sherman, 470p.

Murray, A. 1867. List of Coleoptera received from Old Calabar, on the West Coast of America, Ann. Mag. Nat. Hist., Ser. 3, 20: 314-323.

Pic, M. 1944. Coléoptéres du globe (suite) L'Echange. Rev, Linn., 60(496):5

Schenkling, S. 1914. Beiträge zur Kenntnis der Lymexyloniden (COL.). I. Entomol. Mitteilungen 3:317-321.

Thomson, J. 1858. Voyage au Gabon. Archives Entomologiques, 2: 29-239.

Wheeler, Q. D. 1986. Revision of the Genera of Lymexylidae (Coleoptera: Cucujiformia). Bull. Amer. Mus. Natur. History 183(2): 114-210.

Aceito para publicação em $06 / 12 / 2000$ 